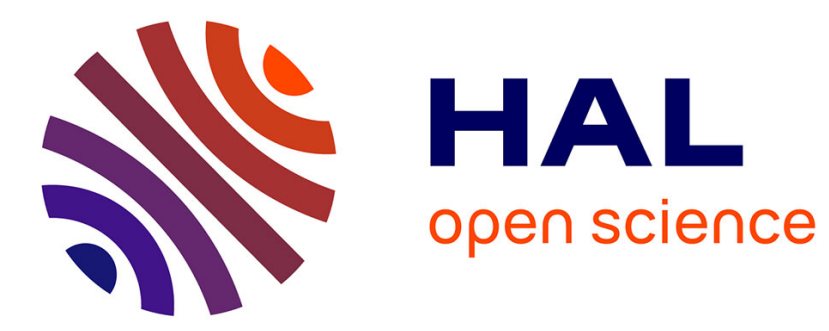

\title{
Silver oxalate-based solders: New materials for high thermal conductivity microjoining
}

Kateryna Kiryukhina, Hoa Le Trong, Philippe Tailhades, Jacques Lacaze, Valérie Baco-Carles, Michel Gougeon, Frédéric Courtade, Sophie Dareys, Olivier Vendier, Lidwine Raynaud

\section{To cite this version:}

Kateryna Kiryukhina, Hoa Le Trong, Philippe Tailhades, Jacques Lacaze, Valérie Baco-Carles, et al.. Silver oxalate-based solders: New materials for high thermal conductivity microjoining. Scripta Materialia, 2013, vol. 68, pp.623-626. 10.1016/j.scriptamat.2012.12.018 . hal-00832138

\section{HAL Id: hal-00832138 https://hal.science/hal-00832138}

Submitted on 10 Jun 2013

HAL is a multi-disciplinary open access archive for the deposit and dissemination of scientific research documents, whether they are published or not. The documents may come from teaching and research institutions in France or abroad, or from public or private research centers.
L'archive ouverte pluridisciplinaire HAL, est destinée au dépôt et à la diffusion de documents scientifiques de niveau recherche, publiés ou non, émanant des établissements d'enseignement et de recherche français ou étrangers, des laboratoires publics ou privés. 


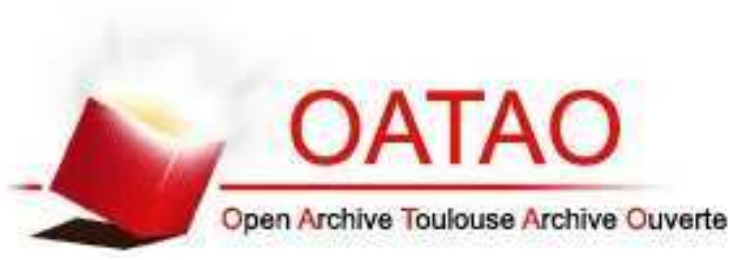

\section{Open Archive TOULOUSE Archive Ouverte (OATAO)}

OATAO is an open access repository that collects the work of Toulouse researchers and makes it freely available over the web where possible.

This is an author-deposited version published in : http://oatao.univ-toulouse.fr/ Eprints ID : 8792

To link to this article : DOI:10.1016/j.scriptamat.2012.12.018

URL : http://dx.doi.org/10.1016/j.scriptamat.2012.12.018

To cite this version :

Kiryukhina, Kateryna and Le Trong, Hoa and Tailhades, Philippe and Lacaze, Jacques and Baco-Carles, Valérie and Gougeon, Michel and Courtade, Frédéric and Dareys, Sophie and Vendier, Olivier and Raynaud, Lidwine Silver oxalate-based solders: New materials for high thermal conductivity microjoining. (2013) Scripta Materialia, vol. 68 ( $\mathrm{n}^{\circ}$ 8). pp. 623-626. ISSN 1359-6462

Any correspondence concerning this service should be sent to the repository administrator: staff-oatao@ listes.diff.inp-toulouse.fr 


\title{
Silver oxalate-based solders: New materials for high thermal conductivity microjoining
}

\author{
K. Kiryukhina, ${ }^{a, b, c, d}$ H. Le Trong, ${ }^{\text {b,e }}$ Ph. Tailhades, ${ }^{\text {b,c,* J. Lacaze, }}{ }^{\text {b,c }}$ V. Baco, ${ }^{\text {b,c }}$ \\ M. Gougeon, ${ }^{\text {b,c }}$ F. Courtade, ${ }^{\mathrm{a}}$ S. Dareys, ${ }^{\mathrm{a}}$ O. Vendier ${ }^{\mathrm{d}}$ and L. Raynaud ${ }^{\mathrm{d}}$ \\ ${ }^{a}$ Centre National d'Etudes Spatiales, 18 Avenue Edouard Belin, 31401 Toulouse Cedex 09, France \\ ${ }^{\mathrm{b}}$ Université de Toulouse, UPS, INP, Institut Carnot CIRIMAT, Université Paul Sabatier, 118 route de Narbonne, \\ 31062 Toulouse Cedex 09, France \\ ${ }^{\mathrm{c}}$ CNRS, Institut Carnot CIRIMAT, F-31062 Toulouse, France \\ ${ }^{\mathrm{d}}$ Thales Alenia Space, 26 Avenue J.-F. Champollion, B.P. 33787, 31037 Toulouse Cedex 01, France \\ ${ }^{\mathrm{e}}$ Ho Chi Minh City University of Science, Vietnam National University Ho Chi Minh City, 227 Nguyen Van Cu Q 5 , \\ 750000 Ho Chi Minh City, Vietnam
}

\begin{abstract}
Micrometric oxalate powders can be decomposed starting from temperatures as low as $90{ }^{\circ} \mathrm{C}$, leading to the formation of temporary nanometric grains of metallic silver with a high propensity for sintering. The decomposition being highly exothermic, this additional energy favours the sintering, i.e. the soldering, process. Solders processed at $300{ }^{\circ} \mathrm{C}$ and very low pressure $(<0.5 \mathrm{MPa})$ displayed a thermal conductivity close to $100 \mathrm{~W} \mathrm{~m}^{-1} \mathrm{~K}^{-1}$, making silver oxalate very promising for safe, moderate temperature and very low pressure bonding.
\end{abstract}

Keywords: Silver oxalate; Microelectronic packaging; Joining; Soldering; Thermal conductivity

Engineering processes often require the joining together of material surfaces using gluing, soldering and brazing [1]. Such joining operations generally involve the supply of a third material (soldering metal, polymeric glue), which must first ensure the bonding between two surfaces, but which can also be dedicated to other functions, such as electrical or thermal conductivity, optical transparency or reflectivity [1]. For interconnections in electronics systems, only a moderate mechanical threshold of bonding is required, but very high electrical or thermal conductivity is often looked for [2,3]. For these reasons, highly conductive metals, such as $\mathrm{Cu}, \mathrm{Ag}, \mathrm{Au}$ and some of their alloys, are used as brazing materials $[3,4]$. However, to benefit from the best electrical or thermal properties of such metals or alloys, they have to be as dense as possible at the end of the brazing operation. This is a difficult challenge,

\footnotetext{
* Corresponding author at: Institut Carnot CIRIMAT, Université Paul Sabatier, 118 route de Narbonne, 31062 Toulouse Cedex 09 , France. Tel.: +33 561556174; fax: +33 561556163; e-mail: tailhade@ chimie.ups-tlse.fr
}

because the brazing operation generally has to be a quite quick (a few minutes) and moderate temperature $\left(\leqslant 300{ }^{\circ} \mathrm{C}\right)$ process, using only light contact pressures between the two pieces for assembly (typically lower than $10 \mathrm{MPa}$ ). Indeed, high temperature and/or pressure processes could cause irreversible damage or accelerated ageing effects to the electronic devices.

To prevent such damage for both dies and substrates, a lot of work has recently been carried out to find low temperature soldering processes and materials [5-10]. One of the driving ideas is to benefit from the strong decrease in the melting temperature when the particle size is reduced below about $10 \mathrm{~nm}$ [11-13]. Because the sintering generally occurs at an absolute temperature close to $80 \%$ of the melting point, this decrease makes low-temperature soldering easier. For gold or silver nanowires, welding can even occur close to room temperature $[7,9]$.

The preparation of silver nanoparticles suspensions or pastes has thus attracted a great deal of attention $[5,6,14,15]$ with regard to developing new joining products. However, such particles must be coated with 
organic compounds to avoid aggregation. Moreover, the industrial use of nanoparticles poses potential health and security problems. Research must thus be carried out to avoid nanoparticles being used in brazing pastes or suspensions. For this reason, combining micrometric silver particles with sintering additives has already been proposed [16].

A new route to obtain highly thermally conductive silver solder at low temperature and pressure is to use suspensions or pastes made of micrometric silver oxalates. Such $\mathrm{Ag}_{2} \mathrm{C}_{2} \mathrm{O}_{4}$ salts can be decomposed into metallic silver below $200{ }^{\circ} \mathrm{C}$ in air, or under an inert or reducing atmosphere $[17,18]$. During this reaction, silver nanoparticles with a high propensity to sinter are created [19]. The oxalate decomposition is highly exothermic $(\Delta H$ close to $-122 \mathrm{~kJ} \mathrm{~mol}^{-1}$ ) [18], providing additional energy locally, which also favours the sintering process. To really take advantage of such oxalic precursors, it is better to prepare particles by chemical precipitation of a soluble salt in oxalic acid dissolved in a hydro-alcoholic medium. By this route, small, well-shaped particles are obtained that can be more easily dispersed in a liquid for suspension or paste manufacturing.

Silver oxalates were prepared as follow. A concentrated solution of silver nitrate was reacted with oxalic acid solution to produce a precipitate of oxalate. The silver nitrate was initially dissolved in a mixture of water $(10 \% \mathrm{vol}$.) and ethylene glycol ( $90 \%$ vol.). For the samples named LE09, the oxalic acid was dissolved in a mixture of ethyl alcohol $(95 \%)$ and water $(5 \%)$. The solvent of the oxalic acid for the samples named LE21, was butanol. The salt solution was then introduced dropwise into the oxalic acid solution. The obtained precipitate was washed several times in deionized water and suspensions were centrifuged to separate the powder from the liquid. Finally, the powder was quickly dried under a primary vacuum and kept away from light due to photosensitive properties. The size of the particles was influenced by the dielectric constant of the solvent. Generally, the size decreases when the dielectric constant of the solvent of oxalic acid is lowered [20]. The use of hydro-alcoholic solvent thus allows small particles to be obtained (Fig. 1), which can be decomposed quickly and easily. The smallest particles, about $1 \mu \mathrm{m}$, were observed for the experiment carried out in butanol (LE21 powder). Consequently, the LE21 sample was used to prepare the brazing suspensions while the LE09 sample, containing acicular particles between 5 and $10 \mu \mathrm{m}$, was used to illustrate the phenomena occurring during decomposition. The same decomposition phenomena were observed for both samples, but the bigger size of particles in the LE09 sample allowed easier electron microscopy imaging of the uncoated low conductive powder.
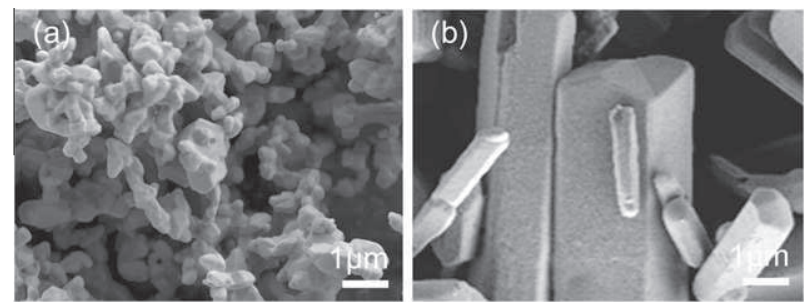

Figure 1. Different morphologies of silver oxalate particles: LE21 sample prepared in butanol (a) and LE09 prepared in ethyl alcohol (b).
The prepared powders display the same X-ray diffraction pattern as the one given by the JCPDS file No. 00022-1335, showing that they are made of a single phase of silver oxalate. The thermal decomposition of one molecule of silver oxalate gives two molecules of metallic silver and two molecules of gaseous $\mathrm{CO}_{2}$, according to the chemical reaction [18]:

$\mathrm{Ag}_{2} \mathrm{C}_{2} \mathrm{O}_{4} \rightarrow 2 \mathrm{Ag}+2 \mathrm{CO}_{2}$

The mass loss after decomposition was equal to $29 \%$, which is the same as the theoretical loss calculated from the chemical reaction (1). The decomposition is a highly exothermic reaction, and can lead to an explosion when the oxalate is quickly heated. However, for a heating rate lower than about $10^{\circ} \mathrm{C} \mathrm{min}^{-1}$, it is possible to avoid an explosion and to stop the reaction in progress at different stages, thus allowing the main features of the decomposition mechanism to be characterized. Oxalate samples were then heated at a constant rate of $5^{\circ} \mathrm{C} \mathrm{min}^{-1}$ to different temperatures before being rapidly cooled. Scanning electron microscopy (SEM) clearly shows the beginning of the decomposition, which starts at a temperature close to $90^{\circ} \mathrm{C}$ with the formation of metallic nanometric-size (below $10 \mathrm{~nm}$ ) grains on the particle edges (Fig. 2a). At $120^{\circ} \mathrm{C}$, numerous spherical or spike-shaped metallic grains were observed on each oxalate particle (Fig. 2b). They are also mainly located on the silver oxalate edges and on surface defects. Indeed, the nucleation activation energy is lower in these areas. Due to the nanometric size of the grains and their related high reactivity, a small increase in temperature to $140^{\circ} \mathrm{C}$ favours their growth and their coalescence (Fig. 2c), leading to the loss of the acicular shape of the precursor particles. At about $200{ }^{\circ} \mathrm{C}$, when the decomposition has finished, spongy metallic grains replace the initial oxalate particles (Fig. 2d). These are partially linked to other decomposed particles by small metallic bridges. Theses bridges reveal the inter-particle sintering process, which can be enhanced at higher temperatures or when the powder is submitted to a small uniaxial pressure.

In order to make a solder paste, suspensions were prepared by mixing silver oxalate powder with pure ethylene glycol in an ultrasonic bath. These were then deposited on the whole surface of a $4 \times 4 \mathrm{~mm}^{2}$ gold-plated alumina
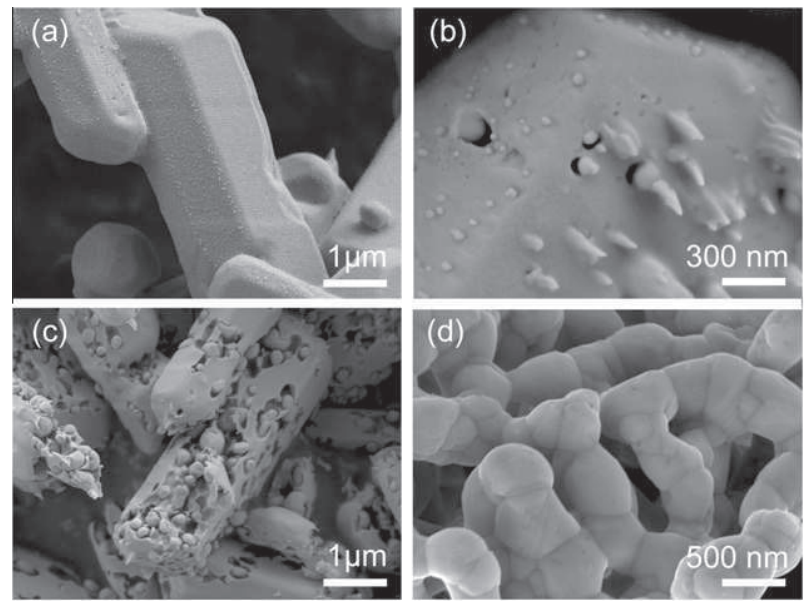

Figure 2. Silver nanoparticles growing and sintering on the surface of LE09 oxalate particles: $90{ }^{\circ} \mathrm{C}$ (a), $120{ }^{\circ} \mathrm{C}$ (b), $140{ }^{\circ} \mathrm{C}$ (c) and $220{ }^{\circ} \mathrm{C}$ (d). 
substrate, mimicking a high-power microchip as used for space applications. After drying, the oxalate film thickness was close to $50 \mu \mathrm{m}$. This "chip" was then covered by another $10 \times 10 \mathrm{~mm}^{2}$ golden alumina sheet, to which a pressure of $<0.5 \mathrm{MPa}$ was applied. The whole assembly was finally heated in air up to $300{ }^{\circ} \mathrm{C}$ and then cooled to room temperature. After this heat treatment, the two gold-plated pieces were strongly joined by a $30 \mu \mathrm{m}$ metallic film. The average shear stress required to separate the two brazed pieces was close to $3 \mathrm{MPa}$, which meets all the requirements in reference to the method MIL Std 883 for die shear strength [21]. The silver solder was controlled by scanning acoustic microscopy. No voids, cracks or thickness heterogeneities were observed by this technique, revealing a good homogeneity of the solder layer.

Due to the $\mathrm{CO}_{2}$ release during the decomposition and the resulting loss of material, the sintering of silver particles at $300{ }^{\circ} \mathrm{C}$ is not complete and a porous metallic network is formed. To reveal this network and to observe its intersection with the bonded parts, the following experiment was carried out. One of the gold-plated alumina substrates was replaced by a very smooth glass slide. Due to both its very small roughness ( $\mathrm{Ra}$ lower than $0.5 \mathrm{~nm}$ ) and its chemical nature (oxide material), this slide was only slightly bonded to the silver after the soldering operation and the two materials were easily separated by a moderate torque. Very few silver grains remained attached to the surface of the glass after splitting, because the bonds between the silver and the glass were much weaker than those inside the solder. SEM and AFM micrographs of the solder can thus show the porous silver network formed at $300{ }^{\circ} \mathrm{C}$ (Fig. 3). Moreover, close observation revealed very flat surfaces on the upper part of some silver grains, which were all located in the same plane. This plane marked the interface between the solder and the glass slide. By image analysis, the surface area of the so-called "flat surfaces" can be measured and its ratio with the total surface area observed, allowing the porosity $p$ of the silver network to be assessed. $p$ was found to be around $80 \%$.

If we assume that $K_{\text {solder }}=K_{\mathrm{Ag}}(1-p)$, with $K_{\text {solder }}$ and $K_{\mathrm{Ag}}$ being the thermal conductivity of the solder and of the bulk silver respectively, $K_{\text {solder }}$ can be estimated to be $(1-0.8) \times 429 \approx 85 \mathrm{~W} \mathrm{~m}^{-1} \mathrm{~K}^{-1}$. This value gives a preliminary rough value of the thermal conductivity, which can be obtained with a silver oxalate-based solder.

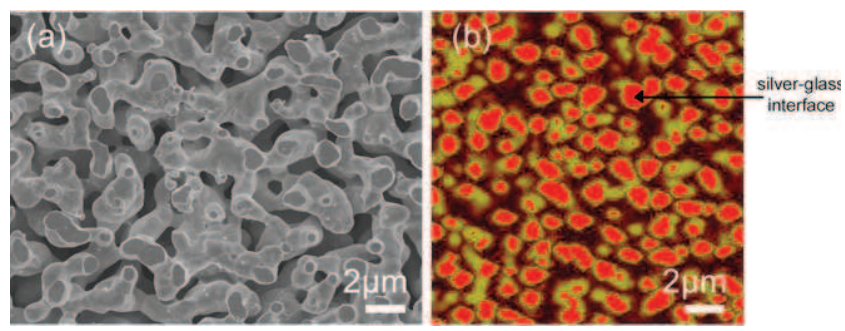

Figure 3. SEM (a) and AFM $\left(30 \times 30 \mu \mathrm{m}^{2}\right)$ images showing the surface of a silver solder after removal of the glass slide positioned on its top. Flat surfaces located in the same plane reveal the silver/glass interface.
To obtain a more precise value and to avoid possible artifacts due to the difference between silver-glass and silver-gold interfaces, thermal conductivity measurements were performed by micro-Raman infrared thermography on active assemblies, in which a high-power microchip was brazed onto a highly conductive goldplated substrate. For this kind of sample, a very low pressure of $<0.5 \mathrm{MPa}$ was applied on the edges of the chip, leaving the active part free. An infrared scan shows a homogeneous temperature repartition in the transistor channel, indicating that the solder layer does not have any major voids. The micro-Raman spectroscopy enables a more precise spatial resolution and was carried out by measuring the temperature and dissipated power of the transistor for each polarization point in DC mode. This information enabled the thermal conductivity of the brazing layer to be calculated, by comparing the measured performance to the computer simulation of the system behaviour. Thermal expansion of the layer and the piezoelectric strain were taken into account. This method gave a thermal conductivity of around $100 \mathrm{~W} \mathrm{~m}^{-1} \mathrm{~K}^{-1}$, which is close to our previous estimation. This value is much higher than those obtained with the widely used AuSn space electronics solder, which are limited to about $57 \mathrm{~W} \mathrm{~m}^{-1} \mathrm{~K}^{-1}$ [22], and is, to our knowledge, the highest obtained at moderate temperature $\left(\leqslant 300^{\circ} \mathrm{C}\right)$ and very low pressure $(<0.5 \mathrm{MPa})$.

It is interesting to note that, when the pressure is increased up to only $3 \mathrm{MPa}$, the porosity drops to about $60 \%$, leading to an estimated value of the thermal conductivity higher than $150 \mathrm{~W} \mathrm{~m}^{-1} \mathrm{~K}^{-1}$.

In summary, this work highlights the potential of silver oxalates precipitated in hydro-alcoholic media as a new soldering material. Such oxalates can be advantageously used to make high thermal conductivity interfaces. For the first time, a solder having a conductivity of about $100 \mathrm{~W} \mathrm{~m}^{-1} \mathrm{~K}^{-1}$, has been obtained at moderate temperature $\left(\leqslant 300{ }^{\circ} \mathrm{C}\right)$ and very low pressure $(<0.5 \mathrm{MPa})$. The performances of the silver oxalatebased solder are explained by the creation of small nanoparticles during thermal decomposition, which considerably improve the material's reactivity. The heat produced by the decomposition also makes the sintering of silver particles easier. In addition, as the initial and final material is of micrometric size, this solder does not require the application of the binding safety procedures required for nanoparticle manipulation, which is a very important advantage of the oxalates compared to products made of silver nanoparticles.

The authors thank Mustafa Faqir and Martin Kuball at the Center for Device Thermography and Reliability H.H. Wills, Physics Laboratory of the University of Bristol, for thermal conductivity measurements.

Supplementary data associated with this article can be found, in the online version, at http://dx.doi.org/ 10.1016/j.scriptamat.2012.12.018.

[1] Y. Zhou, A. Hu, Open Surf. Sci. J. 3 (2011) 32.

[2] Z. Zhang, Lu Guo-Quan, IEEE Trans. Electron. Packag. Manuf. 25 (4) (2002) 279. 
[3] J.S. Kim, P.J. Wang, C.C. Lee, IEEE Trans. Compon. Packag. Technol. 31 (4) (2008) 875.

[4] G. Zou, J. Yan, F. Mu, A. Wu, J. Ren, A. Hu, Y.N. Zhou, Open Surf. Sci. J. 3 (2011) 70.

[5] E. Ide, S. Angata, A. Hirose, K.F. Kobayashi, Acta Mater. 53 (2005) 2385.

[6] K. Maekawa, M. Mita, K. Yamazaki, T. Niizeki, Y. Matsuba, N. Terada, H. Saito, In: Electronic Components and Technology Conference, IEEE Conference Publications, 2008, p. 950.

[7] Y. Lu, J. Yu Huang, C. Wang, S. Sun, J. Lou, Nat. Nanotechnol. 5 (2010) 218.

[8] W.O. Akande, Y. Cao, N. Yao, W. Soboyejo, J. Appl. Phys. 107 (2010) 043519.

[9] E.C. Garnett, W. Cai, J.J. Cha, F. Mahmood, S.T. Connor, M. Greyson Christoforo, Yi Cui, M.D. Mc Gehee, M.L. Brongersma, Nat. Mater. 11 (2012) 241.

[10] M. Ishak, K. Maekawa, K. Yamasaki, Mater. Sci. Eng. A 536 (2012) 143

[11] Ph. Buffat, J.P. Borel, Phys. Rev. A 13 (6) (1976) 13.

[12] A.N. Goldstein, C.M. Echer, A.P. Alivisatos, Science 256 (5062) (1992) 1425.
[13] A. Hu, J.Y. Guo, H. Alarifi, G. Patane, Y. Zhou, G. Compagnini, C.X. Xu, Appl. Phys. Lett. 97 (2010) 153117.

[14] J.G. Bai, Z. Zach Zhang, J.N. Catala, Lu Guo-Quan, IEEE Trans. Compon. Packag. Technol. 29 (3) (2006) 589.

[15] N. Ballarini, F. Cavani, E. Degli Esposito, Z. Sobalik, J. Dedecek, Stud. Surf. Sci. Catal. 175 (2010) 823-826.

[16] W. Schmitt, Electronic System and Integration Technology Conference, 2010, p. 1.

[17] D. Dollimore, T.A. Evans, Thermochim. Acta 1778 (1991) 263.

[18] V.V. Boldyrev, Thermochim. Acta 388 (2002) 63.

[19] G.A. Bratinsky, G.A. Sviridov, A.I. Lesnikovich, in: M.M. Pavliuchenko, I.G. Tishenko (Eds.), Heterogeneous Reactions and Reactivity, Vysshaya shkola, Minsk, 1999, p. 149.

[20] Ph. Tailhades, C. Villette, A. Rousset, G.U. Kulkarni, K.R. Kannan, C.N.R. Rao, M. Lenglet, J. Solid State Chem. 141 (1998) 56.

[21] MIL-STD-883G, 2019.7.

[22] R.R. Tummala, E.J. Rymaszewski, Microelectronics Packaging Handbook, Chapman \& Hall, New York, 1989, p. 37. 